\title{
The predictive role of aortic propagation velocity for coronary artery disease
}

\author{
Fereshteh Ghaderi ${ }^{1}$, Hossein Samim ${ }^{2}$, Faeze Keihanian ${ }^{2,3^{*}}$ (D) and Seyed Ali Danesh Sani ${ }^{4}$
}

\begin{abstract}
Background: It is well recognized that cardio- vascular risk factors lead to histological and functional changes in aorta, and aortic stiffness is the best predictor of cardiovascular morbidity and mortality. In this study we evaluated the relation of a less evaluated echocardiographic parameter of aortic stiffness, aortic propagation velocity (APV) with the presence and severity of CAD.

Methods: This cross sectional study was conducted from May 2015 to March 2016 in Imam Reza hospital, Mashhad, Iran. Seventy patients who were referred for elective coronary artery angiography were enrolled. Patients were divided into two sub-groups based on angiographic findings: patients with CAD (38 patients, 54.3\%) and non-CAD (32 patients, 45.7\%). Transthoracic echocardiography was performed using the conventional 2D and color M-Mode imaging. Aortic propagation velocity (APV), aortic strain (AS) and distensibility (AD) were measured. The presence and Severity of CAD (assessing by syntax score) and their relation with aortic stiffness indices were assessed.

Results: Aortic strain $(6.23 \pm 1.93 \%$ versus $11.66 \pm 4.86 \%, P<0.0001)$, distensibility $(2.46 \pm 0.91$ vs $5.57 \pm 2.25 \mathrm{~cm} 2$ dyn$110-3, P<0.0001)$ and APV $(48.63 \pm 10.31 \mathrm{~cm} / \mathrm{sec}$ vs $77.75 \pm 9.97 \mathrm{~cm} / \mathrm{s}, P<0.0001)$ were significantly decreased in CAD group compared with non-CAD group. In our study, APV showed significant inverse relationship with CAD. Based on our results, APV less than $56 \mathrm{~cm} / \mathrm{sec}$ could be used to predict CAD with sensitivity and specificity of 96.9 and $78.9 \%$ respectively. We also found an inverse correlation between APV and severity of CAD.
\end{abstract}

Conclusion: Aortic strain, AD and APV (a less evaluated echocardiographic index) showed significant inverse correlation with presence and severity of CAD.

Keywords: Arterial stiffness, Aortic propagation velocity, Echocardiography, Coronary artery disease

\section{Background}

As cardiovascular diseases are the leading cause of mortality, the prevention of its complications is a major goal of healthcare. Interest is increasing in finding diagnosis of preclinical vascular involvement in cardiovascular disorders [1]. It is well known that aging and cardiovascular risk factors can alter structure and function of large arteries and their stiffness [2,3]. Aortic stiffness is the best predictor of cardiovascular mortality and morbidity [4, 5]. Invasive assessment of arterial stiffness is not accessible in clinic and non-invasive options such as M-mode

\footnotetext{
* Correspondence: Keihanianf941@mums.ac.ir

${ }^{2}$ Cardiology Resident, Cardiology Department, Faculty of Medicine, Imam Reza and Ghaem Hospitals, Mashhad University of Medical Sciences, Shariati Square, Mashhad, Iran

${ }^{3}$ Clinician Scientist of Cardiology, Pharmaceutical Research Division, Booali Research Center, Mashhad University of Medical Sciences, Mashhad, Iran Full list of author information is available at the end of the article
}

echocardiography has been recommended as a reproducible, accurate, simple and non-expensive technique [6]. Echocardiographic parameters such as aortic strain (AS), aortic distensibility (AD), pulse pressure, augmentation index pulse wave propagation velocity in the detection of aortic stiffness were suggested [7]. Previous studies were evaluated some of these parameters in different status such as atherosclerosis, hypertension, end stage renal disease, patients with chest pain and general population [8]. The literature on the relation between APV and CAD is limited. It is shown that APV in descending aorta in thoracic part is correlated with CAD with conversed pattern $[7,9]$. Higher resistance in aortic wall due to atherosclerosis can indicate a decrement in flow propagation speed in the lumen of arteries [10]. While the extent of coronary artery disease (CAD) increased, the distension of aortic wall and its strain will be

(C) The Author(s). 2018 Open Access This article is distributed under the terms of the Creative Commons Attribution 4.0 International License (http://creativecommons.org/licenses/by/4.0/), which permits unrestricted use, distribution, and 
decreased. The relation between the presence of CAD severity and aortic strain is, also reported [11]. The aim of this study was to investigate the correlation of a less evaluated echocardiographic index of aortic stiffness (APV) with the presence and severity of CAD.

\section{Methods}

\section{Subjects}

The study group consisted of 100 consecutive patients who were referred for elective coronary angiography at our hospital 2015-2016 and divided into a CAD group and a non-CAD group (Fig. 1). A total of 30 patients excluded from the study because the following exclusion criteria: Significant valvular heart disease, known systemic disease affecting aorta (Marfan syndrome, etc.) aortic dilation more than $40 \mathrm{~mm}$, chronic renal failure (CRF: eGFR $<60 \mathrm{ml} / \mathrm{min} / 1.73 \mathrm{~m}^{2}$ ), history of myocardial infarction, $\mathrm{LVEF}<55 \%$, arrhythmia (Every type of ventricular and atrial arrhythmia was excluded and none of participants during the study had APCs or VPCs), bundle branch block (Left and right bundle branch block), suboptimal suprasternal images and refusal of enrollment in the study.

\section{Sample size}

We calculated sample size based on previous study [12] and below formula:

$$
\mathrm{n}=\frac{\left(\mathrm{z}_{1-\alpha / 2}+\mathrm{z}_{1-\beta}\right)^{2}\left(\mathrm{~s}_{1}^{2}+\mathrm{s}_{2}^{2}\right)}{\left(\overline{\mathrm{x}}_{1}-\overline{\mathrm{x}}_{2}\right) 2}
$$

The residual 70 patients composed of 38 patients with obstructive coronary atherosclerosis in CAD group (who had more than $50 \%$ stenosis in at least one coronary artery) and 32 patients in non-CAD group who had normal coronary arteries or less than 50\%coronary artery stenosis. In CAD group extent and severity of CAD was determined by Syntax score. We used SYNTAX score-I for determination of severity of CAD. All patients underwent TTE and APV, AS, AD were measured. An informed consent was given by all patients.

\section{Coronary angiography}

Coronary angiography was performed with Siemens Artis-zee (Siemens Healthcare, Forchheim, Germany) angiography devices. More than $50 \%$ stenotic lesions in left main or main three coronary arteries were considered as obstructive and the number of affected coronary arteries was determined. The severity of CAD was calculated by SYNTAX score I [13].

\section{Transthoracic echocardiographic}

Conventional and color M-mode echocardiography was performed using Philips iE33 (Philips Healthcare, Eindhoven, Netherlands) with $S 5$ probe by an experienced echocardiologist (first author) who was blinded to the angiographic data. M-mode Doppler tracing were recorded at the sweep rate of $200 \mathrm{~mm} / \mathrm{s}$. Three consecutive beats were averaged for every parameter. Ejection fraction, left ventricular end-systolic, and end-diastolic diameters, septal and posterior LV thickness were recorded.

Systolic and diastolic diameters of aorta measurement The systolic and diastolic diameters of the ascending aorta were measured with $\mathrm{M}$ mode echocardiography $3 \mathrm{~cm}$ above the aortic annulus in the parasternal long axis view. The aortic systolic diameter was measured when the aortic valve was fully open and diastolic diameter at the peak of QRS complex on the simultaneously recorded electrocardiogram.

Aortic propagation velocity measurement Color M-mode Doppler tracing were obtained with the cursor

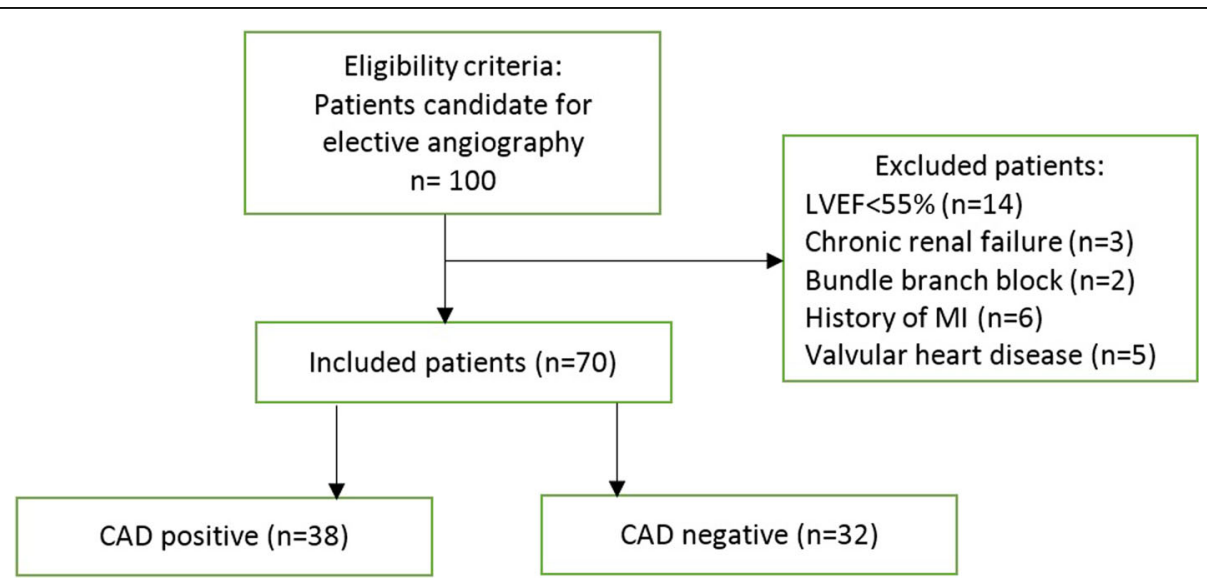

Fig. 1 Flow diagram of study. CAD: coronary artery disease; LVEF: left ventricular ejection fraction; Ml: myocardial infarction 
parallel to the main flow in the lumen of descending aorta from the suprasternal window. The aliasing velocity was adjusted to $30-50 \mathrm{~cm} / \mathrm{s}$. A flame shaped color M-mode image was displayed by switching to M-mode tracing Aortic propagation velocity was measured by tracing the velocity slope of the first aliasing contour (Fig. 2). Systolic and diastolic blood pressure were recorded at the time of echocardiographic exam.

Aortic distensibility and aortic strain measurement AS and AD were calculated based on the formula as below [14]:

$$
\begin{aligned}
& A S(\%) \frac{(\text { aortic systolic diameter-diastolic diameter }) \times 100}{\text { diastolic diameter. }} \\
& A D\left(\mathrm{~cm}^{2} / d y n\right)=\frac{2 \times \mathrm{AS}}{\text { systolic pressure-diastolic pressure }}
\end{aligned}
$$

Estimated glomerular filtration rate (eGFR) measurement Estimated GFR (eGFR) was defined by MDRD formula:

$$
\begin{aligned}
\operatorname{eGFR}\left(\mathrm{mL} / \mathrm{min} / 1.73 \mathrm{~m}^{2}\right) & =186(\mathrm{~S} . \mathrm{Cr} \text { in } \mu \mathrm{mol} / 1 \mathrm{x} 0.011312)^{-1.154} \\
& \mathrm{x}(\text { age })^{-0.203} \mathrm{x}(0.742 \text { if female })
\end{aligned}
$$

\section{Statistics}

All data were entered in SPSS software (Statistical Package for Social Sciences for Windows, version 16.0, Chicago, IL, USA) and analyzed. All descriptive quantitative characteristics were reported as mean \pm standard deviation and qualitative ones reported as percentage and counts. We analyzed normality of distribution for variables using Kolmogorov-Smirnov and Shapiro-Wilk tests. Pearson correlation and chi square tests were used for relationship of qualitative variables. Independent T-Test or One-way ANOVA were used for comparison of quantitative parameters for parametric variables and
Mann Whitney Test for non-parametric ones. Multivariate regression analysis was used for predicting value of aortic stiffness parameters. The value of diagnosis of APV for CAD was evaluated with receiver operating characteristic (ROC) curve. P-Value lower than 0.05 was considered significant.

\section{Ethics}

This study was approved by ethical committee of medical faculty of Mashhad University of Medical Sciences. Ethical code of the study was IR.MUMS.fm. REC.1394.141. All patients filled written informed consent form before entering the study.

\section{Results}

Thirty patients were excluded from the analysis according to exclusion criteria, therefore the statistical analysis included 70 patients. As a result, 38 patients in the CAD group $(54.3 \%)$ and 32 patients $(45.7 \%)$ in the non-CAD group were included. The characteristics of the study population are shown in Table 1 . There were no significant differences between the groups regarding age, gender, BMI and coronary risk factors including hypertension, hyperlipidemia diabetes mellitus, positive family history and smoking status.

Left ventricle end-diastolic and systolic dimension, LV thickness, aortic systolic and diastolic diameters, systolic and diastolic blood pressure, and pulse pressure were not statistically different between the groups. There were significantly difference in $\mathrm{AS}$ and $\mathrm{AD}$ between the groups $(P<0.001)$. (Table 2$)$

APV was significantly lower in CAD rather than non-CAD group $77.75 \pm 9.97 \mathrm{~cm} / \mathrm{sec}$ (range: $55-97 \mathrm{~cm} /$ sec) versus $48.63 \pm 10.31 \mathrm{~cm} / \mathrm{sec}$ (range: $26-78 \mathrm{~cm} / \mathrm{sec}, P$ $<0.0001$ ) respectively. (Table 2 ).

There was positive correlation between APV with AS $(r=0.515, P<0.0001)$ and $\mathrm{AD}(r=0.599, P<0.0001)$.

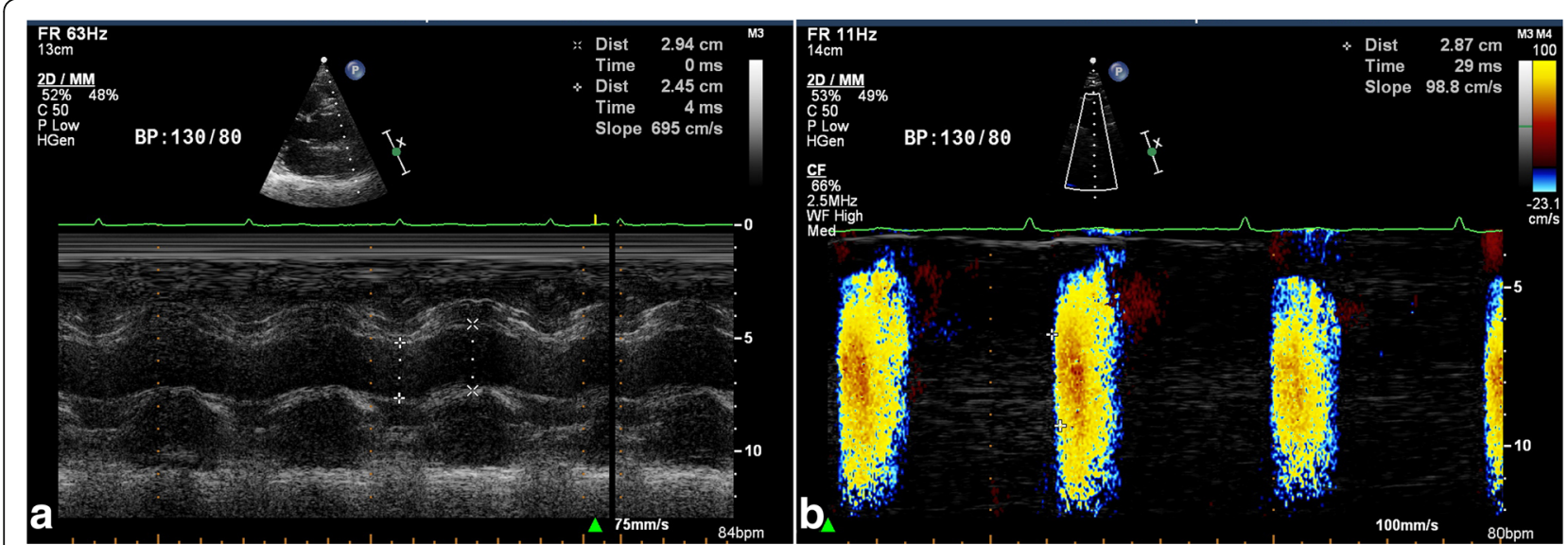

Fig. 2 Measured (A) size of aorta and (B) aortic velocity propagation in a non-CAD case 
Table 1 Comparison of clinical and demographic characteristics of patients in CAD or non-CAD groups

\begin{tabular}{|c|c|c|c|c|}
\hline Characteristics & CAD group $(n=38)$ & Non-CAD group $(n=32)$ & Total $(n=70)$ & $P$-Value \\
\hline Age (year) (mean \pm S.D) & $58.47 \pm 13.29$ & $58.12 \pm 9.65$ & $58.31 \pm 11.69$ & 0.20 \\
\hline Body Mass Index (Kg/m2) & $26.28 \pm 4.65$ & $25.98 \pm 4.38$ & $26.12 \pm 4.48$ & 0.71 \\
\hline Height (cm) & $163.37 \pm 9.27$ & $165.02 \pm 9.57$ & $164.27 \pm 9.40$ & 0.46 \\
\hline Weight (Kg) & $70.06 \pm 15.01$ & $70.28 \pm 13.22$ & $70.18 \pm 13.97$ & 0.52 \\
\hline Heart rate (Per Minute) & $71.62 \pm 8.32$ & $73.47 \pm 12.17$ & $72.62 \pm 10.55$ & 0.45 \\
\hline Systolic blood pressure (mmHg) & $131.71 \pm 14.95$ & $143.02 \pm 20.78$ & $137.85 \pm 19.08$ & 0.10 \\
\hline Diastolic blood pressure $(\mathrm{mmHg})$ & $86.56 \pm 12.40$ & $89.86 \pm 10.99$ & $88.35 \pm 11.69$ & 0.24 \\
\hline Pulse Pressure (mmHg) & $44.84 \pm 14.05$ & $53.68 \pm 16.63$ & $49.64 \pm 16.02$ & 0.21 \\
\hline Hypertension (N, \%) & $23,60.5$ & $18,56.3$ & $41,58.6$ & 0.71 \\
\hline Diabetes mellitus (N, \%) & $11,28.9$ & $10,31.3$ & 21,30 & 0.83 \\
\hline Positive familial history (N, \%) & $13,34.2$ & $6,18.8$ & $19,27.1$ & 0.14 \\
\hline Smoking (N, \%) & $11,28.9$ & $10,31.3$ & 21,30 & 0.87 \\
\hline Hyperlipidemia (N, \%) & $10,26.3$ & 8,25 & $18,25.7$ & 0.90 \\
\hline SYNTAX score & $12.46 \pm 8.62$ & $1.40 \pm 4.11$ & $7.40 \pm 8.89$ & $<0.001$ \\
\hline Left main disease $(\mathrm{N}, \%)$ & $2,5.2$ & 0 & 2,100 & - \\
\hline \multicolumn{5}{|l|}{ Number of involved vessels $(\mathrm{N}, \%)$} \\
\hline Normal coroner & 0 & 32,100 & 32,100 & \\
\hline One-vessel disease & $15,39.4$ & 0 & 15,100 & \\
\hline Two-vessel disease & $9,23.6$ & 0 & $9,23.6$ & \\
\hline Three-vessel disease & $14,36.8$ & 0 & $14,36.8$ & \\
\hline
\end{tabular}

There was significant reverse correlation between number of affected vessels and APV $(r=-0.791, \mathrm{P}<0.0001)$, $\mathrm{AD}(r=-0.620, \mathrm{P}<0.0001)$ and $\mathrm{AS}(r=-0.541, P<$ 0.0001). APV was significantly correlated with Syntax score $(r=-0.791, P<0.0001)$.

Logistic regression analysis showed that APV was the only significant predictor of occurrence of CAD $(P<$ 0.001 , Table 3). Multivariate regression analysis showed that APV $(P<0.001)$ can significantly predict type of CAD involvement (Normal versus one-vessel disease, two-vessel disease or three vessel disease) (Table 4). Based on our results, APV value less than $56 \mathrm{~cm} / \mathrm{sec}$ could be used in predicting CAD with a sensitivity and specificity of 96.9 and $78.9 \%(P<0.001, \mathrm{AUC}=0.972)$, respectively (Fig. 3).

\section{Discussion}

Inflexibility of arterial wall is a marker of vascular aging and a substantial risk factor in progression of atherosclerosis and related cardiovascular disorders. Moreover,

Table 2 echocardiographic findings in CAD and non-CAD groups

\begin{tabular}{llll}
\hline Characteristics & CAD group $n=38$ & Non-CAD group $n=32$ & $P$-Value \\
\hline EF $(\%)$ & $56.34 \pm 2.79$ & $56.56 \pm 2.36$ & 0.81 \\
LVEDD $(\mathrm{cm})$ & $4.89 \pm 0.32$ & $4.76 \pm 0.43$ & 0.73 \\
LVESD $(\mathrm{cm})$ & $3.00 \pm 0.45$ & $2.87 \pm 0.40$ & 0.23 \\
PWT $(\mathrm{cm})$ & $0.80 \pm 0.09$ & $0.79 \pm 0.08$ & 0.48 \\
ST $(\mathrm{cm})$ & $0.87 \pm 0.12$ & $0.83 \pm 0.10$ & 0.14 \\
Diastolic diameter (cm) & $2.93 \pm 0.35$ & $2.92 \pm 0.23$ & 0.69 \\
Systolic diameter $(\mathrm{cm})$ & $3.14 \pm 0.30$ & $3.26 \pm 0.24$ & 0.76 \\
AS (\%) & $6.23 \pm 1.93$ & $11.66 \pm 4.86$ & $<0.0001$ \\
AD $\left(\mathrm{cm}^{2}{ }^{2} \mathrm{dyn}^{-1}{ }^{-3}\right)$ & $2.46 \pm 0.91$ & $5.57 \pm 2.25$ & $<0.0001$ \\
APV & $48.63 \pm 10.31$ & $77.75 \pm 9.97$ & $<0.0001$ \\
\hline
\end{tabular}

EF Ejection fraction; LVEDD Left ventricular end diastolic diameter; LVESD Left ventricular end systolic diameter; PWT Posterior wall thickness; ST Septal thickness; $A S$ Aortic strain; $A D$ Aortic distentibility; APV Aortic propagation velocity 
Table $\mathbf{3}$ Logistic regression analysis

\begin{tabular}{llllllll}
\hline Characteristics & $B$ & S.E. & Wald & Sig. & $\operatorname{Exp}(\mathrm{B})$ & \multicolumn{2}{c}{$95 \% \mathrm{Cl}$} \\
\cline { 6 - 8 } & & & & & & Lower & Upper \\
\hline SBP & -0.006 & 0.058 & 0.010 & 0.922 & 0.994 & 0.888 & 1.114 \\
PP & -0.021 & 0.153 & 0.020 & 0.889 & 0.979 & 0.726 & 1.320 \\
AS & -0.240 & 0.872 & 0.075 & 0.784 & 0.787 & 0.142 & 4.349 \\
AD & -1.048 & 2.133 & 0.241 & 0.623 & 0.351 & 0.005 & 22.945 \\
APV & -0.252 & 0.085 & 8.787 & $<0.001$ & 0.777 & 0.658 & 0.918 \\
\hline SBP Systolic blood pressure; PP Pulse pressure; AS Aortic stiffness; AD Aortic \\
distentibility; APV Aortic propagation velocity
\end{tabular}

it has been mentioned before that this index is related to cardiovascular risk factors, such as smoking, hypertension, obesity, diabetes mellitus, lipid profile dysfunction and higher age $[10,15,16]$. Arterial stiffness is determined by structural and functional constituents of elastic features and influences blood pressure. This study evaluated the predictive value of APV and other arterial stiffness factors in patients with CAD and compared the results with non-CAD patients. To the best of the author's knowledge, there are limited studies in this field and there is no study in Iran that has assessed the SYNTAX score and arterial stiffness.

In the current study, the researchers determined that APV is significantly lower in the CAD group (48.63 \pm $10.31 \mathrm{~cm} / \mathrm{s})$ compared with the non-CAD group $(77.75$ $\pm 9.97 \mathrm{~cm} / \mathrm{s}$ ). This is similar to other studies. Yildrim et al. also showed that APV level in patients with severe risk factors in the past 10 years $(37 \pm 13 \mathrm{~cm} / \mathrm{s})$ was lower than patients with moderate or low risk factors [17]. Gunes et al. showed lower APV in CAD $(29.9 \pm 8.1 \mathrm{~cm} /$ s) in comparison with the normal coronary group (47.5 $\pm 16.8 \mathrm{~cm} / \mathrm{s}$ ) [18]. This indicates that decreasing APV is related to risk factors and chronicity, similar to the results of the present study. Sen et al. also demonstrated lower levels of APV in CAD $(39.2 \pm 13.9 \mathrm{~cm} / \mathrm{s})$ in comparison with non-CAD subjects $(81.4 \pm 21.4 \mathrm{~cm} / \mathrm{s})$ [12]. Chetty et al.'s study was also in accordance with the current results and showed a significant decrease of $\mathrm{APV}$ in $\mathrm{CAD}(41.65 \pm 4.94 \mathrm{~cm} / \mathrm{s})$ rather than non-CAD $(49.72 \pm 6.38 \mathrm{~cm} / \mathrm{s})$ group [19]. These findings support the hypothesis that APV has a role in atherosclerotic events and arterial stiffness. It is important to note that although the 'flow propagation of velocity' is not a real calculation of fluid propagation between base and apex, there is a relationship with maximal detected velocity points. These results may be representative of various fluid components, which can concurrently be stimulated by local pressure gradient at various depths in front of the inflow tract [20]. As arterial stiffness is increased, APV will be decreased and this can be an early index in symptomless arterial stiffness.

Another major finding was the inverse correlation between severity of CAD (by SYNTAX score) and APV. This has not been extensively evaluated by previous studies. Only one study showed that APV has a strong and inverse correlation with the SYNTAX score [19]. Other studies used the Gensini score for severity of CAD. However, SYNTAX score has greater agreement with the guidelines when compared with the Gensini score. Sen et al. [12] and Gunes et al. [9] showed no significant correlation between severity of CAD (by Gensini score) and APV. This correlation can be representative of the severity of CAD without any intervention and could be very helpful. However, future studies on this subject are required.

Another important finding of the current study was the predictive value of APV in CAD with high sensitivity and specificity with cutoff point of $56 \mathrm{~cm} / \mathrm{s}$. Yildirim et al. reported a cutoff value of $46.5 \mathrm{~cm} / \mathrm{s}$ with sensitivity and specificity of 84 and $85 \%$ for APV [17]. Chetty et al. showed a cutoff point of $47.5 \mathrm{~cm} / \mathrm{s}$ with sensitivity and specificity of 76 and $72 \%$ for APV in predicting CAD [19]. Sen et al. also showed that only APV could independently predict CAD with sensitivity and specificity of 90.5 and $92.2 \%$ and with cutoff point of $60.5 \mathrm{~cm} / \mathrm{s}$ [12]. The current results and other previous studies showed a spectrum of cutoff points that are almost similar and can significantly predict the CAD.

The current researchers found that there was a positive correlation between APV and AS and APV and AD. There was a negative correlation between APV, SBP and DBP. Devici et al. reported on a significantly different

Table 4 Multivariate regression analysis

\begin{tabular}{|c|c|c|c|c|c|}
\hline \multirow[t]{2}{*}{ Characteristics } & \multicolumn{2}{|c|}{ Unstandardized Coefficients } & \multirow{2}{*}{$\begin{array}{l}\text { Standardized Coefficients } \\
\text { Beta }\end{array}$} & \multirow[t]{2}{*}{ t } & \multirow[t]{2}{*}{ Sig. } \\
\hline & B & Std. Error & & & \\
\hline SBP & -0.003 & 0.003 & -0.104 & -0.946 & 0.348 \\
\hline PP & 0.002 & 0.005 & 0.064 & 0.414 & 0.680 \\
\hline $\mathrm{FH}$ & 0.073 & 0.076 & 0.066 & 0.970 & 0.336 \\
\hline AS & -0.012 & 0.019 & -0.105 & -0.630 & 0.531 \\
\hline$A D$ & -0.046 & 0.042 & -0.210 & -1.100 & 0.276 \\
\hline APV & -0.019 & 0.002 & -0.659 & -8.097 & $<0.0001$ \\
\hline
\end{tabular}

SBP Systolic blood pressure; PP Pulse pressure; AS Aortic stiffness; AD Aortic distentibility; FH Familial history; APV Aortic propagation velocity 


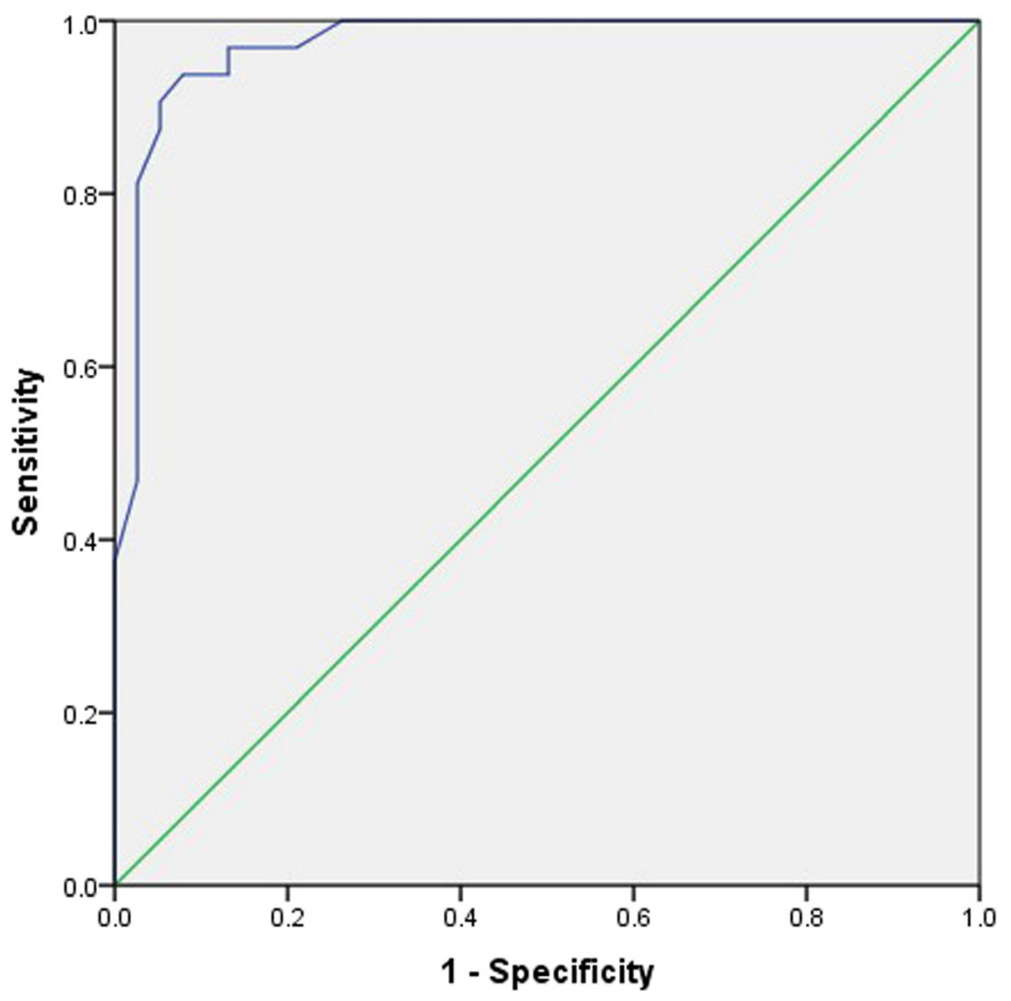

Fig. 3 the ROC curve of APV in predicting CAD. Area under the curve (AUC) for APV: 0.972

AS, AD, and APV in three groups and a significant relationship between APV, AS and AD and coronary ectasia score [21]. Chetty et al. also showed an inverse relation between APV and SBP, age, duration of diabetes and low LDL, which was only significant in SBP [19]. Sen et al.'s results were in line with the current findings and showed a positive correlation between APV and AS and AD [12]. This shows the correlation of arterial stiffness parameters that were in the same direction and could influence each other.

The current investigation had some limitations. Although the authors showed a good prediction by APV for CAD, a poor view in suprasternal window in echocardiography could lead to low quality images and this can result in low reproducibility of this technique. This protocol of this study was affected by age, weight, obesity, and anatomy of aorta of patients and limited access in some cases. The authors did not evaluate other parameters, such as Carotid Intima-Media Thickness (CIMT).

\section{Conclusion}

We showed that the novel transthoracic color M-Mode, APV can significantly predict the CAD. This method is practical echocardiographic, noninvasive, simple economical approach for detecting or screening CAD. It also may be beneficial for CAD comorbidities and risk stratification and selection of high-risk individuals for CAD. One of the major important new findings of our study was the correlation between the severity of CAD with SYNTAX score and arterial stiffness. This could help physicians to make prognosis for angiographic severity of CAD. This is the first study in Iran and second study in the world that is based on new guideline of SYNTAX score which is best validated. Large scale population, multi-centric studies are recommended to validate the applicability of the method as a screening tool.

\section{Abbreviations}

AD: Aortic distensibility; APV: Aortic propagation velocity; AS: Aortic strain; CAD: Coronary artery disease; CIMT: Carotid intima-media thickness; eGFR: Estimated Glomerular Filtration Rate; LV: Left Ventricle; LVEF: Left ventricular ejection fraction; ROC: Receiver operating characteristic; TTE: Transthoracic echocardiography

\section{Acknowledgements}

The authors thank all nurses at the Imam Reza Hospital for their assistance with the data collection and cooperation in performing this project.

Funding

This study was funded by Mashhad University of Medical Sciences.

\section{Availability of data and materials}

The datasets used or analyzed in the current study are available from the corresponding author on reasonable request. 


\section{Authors' contributions}

Dr. F.Gh designed the study, prepared the first draft of the manuscript, analyzed the echocardiographic views, and read and approved the final version of the manuscript. Dr. H.S collected the data, filled the checklists and read and approved the final version of the manuscript. Dr. F.K participated in analysis of results and development of study, wrote the first draft of the manuscript, and read and approved the final version. Dr. SA.DS participated in data collection, writing of the first draft and approved the final version. All authors read and approved the final manuscript.

\section{Ethics approval and consent to participate}

This study was approved by the ethical committee of the medical faculty of Mashhad University of Medical Sciences. The ethical code of the study was IR.MUMS.fm.REC.1394.141. All patients filled a written informed consent form before entering the study.

\section{Competing interests}

The authors declare that they have no competing interests.

\section{Publisher's Note}

Springer Nature remains neutral with regard to jurisdictional claims in published maps and institutional affiliations.

\section{Author details}

${ }^{1}$ Fellowship in echocardiography, Cardiology Department, Imam Reza Hospital, Faculty of Medicine, Mashhad University of Medical Sciences, Mashhad, Iran. ${ }^{2}$ Cardiology Resident, Cardiology Department, Faculty of Medicine, Imam Reza and Ghaem Hospitals, Mashhad University of Medical Sciences, Shariati Square, Mashhad, Iran. ${ }^{3}$ Clinician Scientist of Cardiology, Pharmaceutical Research Division, Booali Research Center, Mashhad University of Medical Sciences, Mashhad, Iran. ${ }^{4}$ General Practitioner, Cardiology department, Faculty of Medicine, Imam Reza Hospital, Mashhad University of Medical Sciences, Mashhad, Iran.

Received: 18 October 2017 Accepted: 6 June 2018

Published online: 19 June 2018

\section{References}

1. Koskinen J, Magnussen CG, Taittonen L, Räsänen L, Mikkilä V, Laitinen T, et al. Arterial structure and function after recovery from the metabolic syndrome. Circulation. 2010;121(3):392-400.

2. Mitchell GF, Parise H, Benjamin EJ, Larson MG, Keyes MJ, Vita JA, et al. Changes in arterial stiffness and wave reflection with advancing age in healthy men and women. Hypertension. 2004;43(6):1239-45.

3. Haluska BA, Jeffriess L, Downey M, Carlier SG, Marwick TH. Influence of cardiovascular risk factors on total arterial compliance. J Am Soc Echocardiogr. 2008;21(2):123-8.

4. Arnett DK, Evans GW, Riley WA. Arterial stiffness: a new cardiovascular risk factor? Am J Epidemiol. 1994;140(8):669-82.

5. Sethi S, Rivera O, Oliveros R, Chilton R. Aortic stiffness: pathophysiology, clinical implications, and approach to treatment. Integr Blood Press Control. 2014;7:29.

6. Leitman M, Lysyansky P, Sidenko S, Shir V, Peleg E, Binenbaum M, et al. Two-dimensional strain-a novel software for real-time quantitative echocardiographic assessment of myocardial function. J Am Soc Echocardiogr. 2004;17(10):1021-9.

7. Simsek H, Sahin M, Gunes Y, Akdag S, Akil M, Akyol A, et al. A novel echocardiographic method as an indicator of endothelial dysfunction in patients with coronary slow flow. Eur Rev Med Pharmacol Sci. 2013;17(5): 689-93.

8. Achimastos A, Benetos A, Stergiou G, Argyraki K, Karmaniolas K, Thomas F, et al. Determinants of arterial stiffness in Greek and French hypertensive men. Blood Press. 2002:11(4):218-22.

9. Gunes $Y$, Tuncer M, Guntekin U, Ceylan Y, Simsek H, Sahin M, et al. The relation between the color M-mode propagation velocity of the descending aorta and coronary and carotid atherosclerosis and flow-mediated dilatation. Echocardiography. 2010;27(3):300-5

10. Akdag S, Akyol A, Cakmak HA, Gunbatar H, Asker M, Babat N, et al. A novel echocardiographic method for assessing arterial stiffness in obstructive sleep apnea syndrome. Korean Circ J. 2015;45(6):500-9.
11. Yildiz A, Gur M, Yilmaz R, Demirbag R. The association of elasticity indexes of ascending aorta and the presence and the severity of coronary artery disease. Coron Artery Dis. 2008;19(5):311-7.

12. Sen T, Tufekcioglu O, Ozdemir M, Tuncez A, Uygur B, Golbasi Z, et al. A new echocardiographic parameter of aortic stiffness and atherosclerosis in patients with coronary artery disease: aortic propagation velocity. J Cardiol. 2013;62(4):236-40

13. Ayça B, Akın F, Çelik Ö, Çetin \$, Şahin I, Gülşen K, et al. Does SYNTAX score predict in-hospital outcomes in patients with ST elevation myocardial infarction undergoing primary percutaneous coronary intervention? Kardio Polska (Polish Heart J). 2014;72(9):806-13.

14. Lacombe F, Dart A, Dewar E, Jennings G, Cameron J, Laufer E. Arterial elastic properties in man: a comparison of echo-Doppler indices of aortic stiffness. Eur Heart J. 1992;13(8):1040-5.

15. Flemons W, Buysse D, Redline S, Oack A, Strohl K, Wheatley J, et al. Sleeprelated breathing disorders in adults. Sleep. 1999;22(5):667-89.

16. Shahar E, Whitney CW, Redline S, Lee ET, Newman AB, Javier Nieto F, et al. Sleep-disordered breathing and cardiovascular disease: cross-sectional results of the sleep heart health study. Am J Respir Crit Care Med. 2001; 163(1):19-25.

17. Yıldırım M, Yiginer O, Uzun M, Cingozbay BY, Sag C, Kutsi H, et al. Aortic flow propagation velocity as an early predictor of high coronary risk in hypertensive patients. Medicinski glasnik: official publication of the Medical Association of Zenica-Doboj Canton, Bosnia and Herzegovina. 2012;9(1).

18. Gunes Y, Tuncer M, Yildirim M, Guntekin U, Gumrukcuoglu HA, Sahin M. A novel echocardiographic method for the prediction of coronary artery disease. Med Sci Monit. 2008;14(9):MT42-MT6.

19. Chetty PV, Rajasekhar D, Vanajakshamma V, Ranganayakulu KP, Chaithanya DK. Aortic velocity propagation: a novel echocardiographic method in predicting atherosclerotic coronary artery disease burden. J Saudi Heart Assoc. 2017;29(3):176-84.

20. Sessoms MW, Lisauskas J, Kovács SJ. The left ventricular color M-mode Doppler flow propagation velocity $\mathrm{V}$ p: in vivo comparison of alternative methods including physiologic implications. J Am Soc Echocardiogr. 2002; 15(4):339-48.

21. Deveci E, Kaya Z, Günebakmaz Ö, Sezen Y, Yeşilay AB, Erkuş E, et al. Investigation of aortic elastic parameters [aortic Distensibility and aortic strain] and aorta propagation velocity in the coronary ectasia patients with or without critical coronary artery disease. J Am Coll Cardiol. 2013;62(18):C11.

\section{Ready to submit your research? Choose BMC and benefit from:}

- fast, convenient online submission

- thorough peer review by experienced researchers in your field

- rapid publication on acceptance

- support for research data, including large and complex data types

- gold Open Access which fosters wider collaboration and increased citations

- maximum visibility for your research: over $100 \mathrm{M}$ website views per year

At BMC, research is always in progress.

Learn more biomedcentral.com/submissions 